\title{
Inflammation-associated cancer development in digestive organs: mechanisms and roles for genetic and epigenetic modulation.
}

\section{$\operatorname{AUTHOR}(S)$ :}

Chiba, Tsutomu; Marusawa, Hiroyuki; Ushijima, Toshikazu

\section{CITATION:}

Chiba, Tsutomu ...[et al]. Inflammation-associated cancer development in digestive organs: mechanisms and roles for genetic and epigenetic modulation.. Gastroenterology 2012, 143(3): 550-563

ISSUE DATE:

2012-09

URL:

http://hdl.handle.net/2433/160134

\section{RIGHT:}

(C) 2012 AGA Institute. Published by Elsevier Inc.; This is not the

published version. Please cite only the published version.; この論文は

出版社版でありません。引用の際には出版社版をご確認ご利用くださ い。 


\title{
Inflammation-Associated Cancer Development
}

\section{in Digestive Organs: Mechanisms and Roles for Genetic and Epigenetic Modulation-}

Tsutomu Chiba*, Hiroyuki Marusawa* and Toshikazu Ushijimał

*Department of Gastroenterology and Hepatology, Graduate School of Medicine, Kyoto University, Kyoto, and \$Division of Epigenomics, National Cancer Center Research Institute, Tokyo, Japan

\begin{abstract}
Chronic inflammation, regardless of infectious agents, plays important roles in the development of various cancers particularly in digestive organs, including Helicobacter pylori (H. pylori)-associated gastric cancer, hepatitis $\mathrm{C}$ virus (HCV)-positive hepatocellular carcinoma, and colitis-associated colon cancers. Cancer development is characterized by stepwise accumulation of genetic and epigenetic alterations of various proto-oncogenes and tumor suppressor genes. During chronic inflammation, infectious agents such as $H$. pylori and $\mathrm{HCV}$ as well as intrinsic mediators of inflammatory responses, including proinflammatory cytokines and reactive oxygen and nitrogen species, can induce genetic and epigenetic changes, including point mutations, deletions, duplications, recombinations, and methylation of various tumor-related genes through various mechanisms. Furthermore, inflammation also modulates the expressions of microRNAs that influence the production of several tumor-related mRNAs or proteins. These molecular events induced by chronic inflammation work in concert to alter important pathways involved in normal cellular function, and hence accelerate inflammation-associated cancer development. Among these, recent studies highlighted an important role of activation-induced cytidine deaminase, a nucleotide-editing enzyme essential for somatic hypermutation and class-switch recombination of the immunoglobulin gene, as a genomic modulator in inflammation-associated cancer development.
\end{abstract}

Keywords: Inflammation; Cancer; H. pylori; HCV; Mutation Induction; Epigenetics; DNA methylation; microRNA; Activation-Induced Cytidine Deaminase (AID). 
Abbreviations used in this paper: 5-mC, 5-methyl cytosine; 8-OHdG, 8-hydroxydeoxyguanosine; A, adenine; AID, activation-induced cytidine deaminase; APC, adenomatous polyposis coli; AUC, area under the curve; Basp1, brain abundant, membrane attached signal protein 1; BCR, breakpoint cluster region; C, cytosine; cagPAI, cytotoxin-associated gene pathogenicity island; CD40, cluster of differentiation 40- TNF receptor superfamily member 5; CDH1, cadherin-1; CDKN, cyclin-dependent kinase inhibitor; $\mathrm{COX}-2$, cyclooxygenase 2; $\mathrm{Cxcl} 2$, chemokine (C-X-C motif) ligand 2; DNMT, DNA methyltransferase; DSS, dextran sulfate sodium; EGF, epidermal growth factor; ERK, extracellular signal-regulated kinase; EZH2, enhancer of zeste homolog 2; FIH-1, regulating factor inhibiting hypoxia inducible factor 1; FLNc, filamin $\mathrm{C} \gamma ; \mathrm{G}$, guanine; $\mathrm{H}$, histone; HBV, hepatitis $\mathrm{B}$ virus; $\mathrm{HCC}$, hepatocellular carcinoma; HCV, hepatitis $\mathrm{C}$ virus; HIF-1, hypoxia-inducible factor-1; IBD, inflammatory bowel disease; $\mathrm{IGH}$, immunoglobulin $\mathrm{H}$; IKK, I- $\mathrm{B}$ B kinase; iNOS, inducible nitric oxide synthase; IL-1 $\beta$, interleukin-1 $\beta$; IFN, interferon; JNK, c-Jun N-terminal kinase; Let-7, lethal-7; Lphn2, latrophilin 2; LPS, lipopolysaccharide; Mafg, musculoaponeurotic fibrosarcoma oncogene homolog; MALT, mucosa-associated lymphatic tissue; miRNA, microRNA; MAPK, mitogen activated protein kinase; MBD4, methyl-CpG binding domain protein 4; miR-7, microRNA-7; MLH1,mutL homolog 1; MSH2, mutS homolog 2; MSH6, mutS homolog 6 ; NF- $\kappa \mathrm{B}$, activation of transcription factor nuclear factor $\kappa \mathrm{B}$; NLRs, nod-like receptors; PDCD4, programmed cell death 4; PSC, primary sclerosing cholangitis; PTEN, phosphatase and tensin homolog; RASSF1A, RAS-association domain family 1 , isoform $\mathrm{A}$; $\mathrm{RB}$, retinoblastoma protein; RNS, reactive nitrogen species; ROC, Receiver-operating characteristic; ROS, reactive oxygen species; SCID, severe combined immunodeficiency; STAT3, signal transducer and activator of transcription 3; SIRT1, sirtuin 1; STAT6, signal transducer and activator of transcription 6; SVR, sustained virological response; T, thymine; Th2, T helper 2 cell; THDB, thrombomodulin; TET1, ten-eleven translocation 1; TLRs, toll-like receptors; TNF- $\alpha$, tumor necrosis factor- $\alpha$; U, uracil; UNG, uracil DNA glycosylase; WEE1, mitosis inhibitor protein kinase 


\section{Introduction}

Nearly 150 years ago, Rudolf Virchow noted that inflammatory cells are present in tumor tissues and that tumors develop at sites of chronic inflammation; he suggested that chronic inflammation plays important roles in cancer development. Since then, many clinical and epidemiological studies have confirmed a strong association between inflammation and cancer $^{1,2}$. For instance, epidemiological studies have shown that approximately $10-15 \%$ of cancers were related to chronic infections with viruses, bacteria or parasites ${ }^{3-7}$, and moreover, that up to $25 \%$ of all cancers were associated with chronic inflammation irrespective of the presence or absence of infection ${ }^{5-7}$.

In inflammation-associated cancer development, in addition to infectious agents such as Helicobacter pylori (H. pylori) and hepatitis $\mathrm{C}$ virus (HCV), many intrinsic mediators of inflammation including proinflammatory cytokines, eicosanoids, growth factors, and reactive oxygen species (ROS) and reactive nitrogen species (RNS) exert important effects in cancer development through various mechanisms. These include enhancement of cell growth and mobility, induction of angiogenesis, and inhibition of apoptosis. However, a hallmark of cancer development is the stepwise accumulation of various genetic and epigenetic alterations of the genome. Indeed, recent genome-wide analysis of human cancer tissues revealed that a single cancer cell generally possesses approximately 100 mutations in coding regions, 10-20 of which are known as "driver genes" that contribute to cancer development ${ }^{8-10}$, and moreover, that there are many somatic gene rearrangements, including duplications, deletions and inversions in human cancer genomes ${ }^{11,12}$. In addition to genetic alterations, recent studies have also shown that chronic inflammation enhances epigenetic changes as represented by DNA methylation ${ }^{13}$. It is estimated that several hundreds to thousands of genes are methylated in a cancer cell ${ }^{14}$, and that aberrant DNA methylation is present even in normal-appearing tissues, being involved in field cancerization ${ }^{13,15,16}$.

Digestive organs are inhabited by many microorganisms and are infiltrated by many immune cells in physiological and pathological conditions, and thus they are more or less accompanied by certain levels of inflammation. Here, we review mechanisms of how inflammation is involved in cancer development in digestive organs, particularly focusing on the role of chronic inflammation in inducing genetic and epigenetic changes.

\section{Cancers in Digestive Organs Associated with Inflammation}


Many cancers arise in digestive organs. Indeed, gastric cancer remains the third leading cause of cancer death in men and the fifth in women, and colorectal cancer is the third most commonly diagnosed cancer in men and the second most in women world-wide ${ }^{17}$. In addition, hepatocellular carcinoma (HCC) is one of the most frequent malignancies and its incidence is increasing not only in an endemic area for the hepatitis virus but also in the United States and other western countries ${ }^{18}$. Digestive organs cover a large part of the body surface in contact with the outer environment. Accordingly, they are not only inhabited by many microorganisms but also exposed to ingested food or chemical agents, and therefore infiltrated by many immune cells in pathological as well as normal conditions, supporting the perpetuation of chronic inflammation. Therefore, it is reasonable that many cancers in digestive organs are associated with inflammation.

The best examples of inflammation-associated cancer in humans are gastric cancer and HCC. Since the discovery of H. pylori by Warren and Marshall in $1982^{19}$, it has been well established that $H$. pylori-positive patients with chronic gastritis have a significantly higher risk for gastric cancer than $H$. pylori-negative subjects ${ }^{20}$, and moreover, careful investigations have shown more than $95 \%$ positivity for $\mathrm{H}$. pylori infection in gastric cancer patients ${ }^{21}$. On the other hand, hepatitis B virus (HBV) and $\mathrm{HCV}$ infections account for approximately $60 \%$ and $33 \%$ of the total HCC cases in developing countries and $23 \%$ and $20 \%$ in developed countries, respectively ${ }^{6,22}$, and the majority of HCCs develop in patients who have chronic hepatitis or liver cirrhosis. Other inflammation-associated cancers in digestive organs are colitic cancers developed in patients with inflammatory bowel disease (IBD) or celiac disease ${ }^{23-25}$, primary sclerosing cholangitis (PSC)-associated cholangiocarcinoma ${ }^{26}$, primary biliary cirrhosis-associated $\mathrm{HCC}^{27}$, and Barrett's cancer developed in patients with reflux esophagitis $^{28}$. In addition, the incidence of pancreatic cancer in patients with chronic pancreatitis is reported to be 4-8 times higher than in the general population ${ }^{29}$, and more strikingly, the incidence of pancreatic cancer in patients with hereditary pancreatitis is 53 times higher than in the normal population ${ }^{30}$, indicating that chronic pancreatitis is a risk for pancreatic cancer.

In addition to cancers, inflammation is also a risk for developing various lymphomas in digestive organs. These include $H$. pylori-induced mucosa-associated lymphatic tissue (MALT) lymphoma or plasmacytoma ${ }^{31,32}$, HCV-related lymphoma ${ }^{33}$, and lymphoma related to celiac disease ${ }^{34}$.

\section{Mechanisms for Inflammation-Associated Cancer Development}


The inflammatory response is coordinated by a large range of mediators, which are released from immune cells, mesenchymal cells and epithelial cells; these mediators exert various functions in maintaining or resolving inflammation, and at the same time are involved in cancer development. Among the mediators, cytokines play central roles in diversifying the inflammatory process, and interleukin (IL)- $1 \beta$, tumor necrosis factor (TNF)- $\alpha$, and IL-6 are known to be the major cytokines important for inflammation and cancer development ${ }^{35-37}$.

IL1- $\beta$ and TNF- $\alpha$ act directly on epithelial cells to induce activation of transcription factor nuclear factor- $\kappa \mathrm{B}(\mathrm{NF}-\kappa \mathrm{B})$, a key transcription factor mediating inflammation and cancer development ${ }^{36,37}$. NF- $\kappa \mathrm{B}$ activation not only promotes growth or suppresses apoptosis of epithelial cells but also stimulates the production of growth factors and cytokines such as epidermal growth factor (EGF) and IL-6, enhances cyclooxygenase (COX)2 induction, and increases ROS production ${ }^{38}$. The induced COX-2 subsequently has many functions, including enhancement of cell growth and angiogenesis $^{39}$. ROS modifies protein function ${ }^{40}$. IL-6 activates signal transducer and activator of transcription 3 (STAT3) and thereby enhances cell growth, and stimulates growth factor production, including the Reg protein ${ }^{41}$. Interestingly, TNF- $\alpha$ and IL-6 often create a positive-feedback loop during cancer development ${ }^{42}$.

At the same time, these cytokines also activate mitogen-activated protein kinase (MAPK) cascades. For instance, TNF- $\alpha$ and IL-6 have been shown to activate the extracellular signal-regulated kinase (ERK)/MAPK cascade, an important signaling pathway involved in many processes in carcinogenesis including cell proliferation, migration, and angiogenesis ${ }^{43,44}$. Similarly, IL1- $\beta$, TNF- $\alpha$, and IL-6 all activate c-Jun $\mathrm{N}$-terminal kinase (JNK). Although JNKs are primarily attributed to proapoptotic cell death or tumor suppression in response to inflammation or various stressors ${ }^{45}$, JNK activation, particularly JNK1, by proinflammatory cytokines has been reported to contribute to inflammation-associated cancer development through cell death-induced "compensatory proliferation"45-48. In this regard, an interesting thing to note is that $H$. pylori directly activates ERK/MAPK and JNK in human gastric cells via a type IV secretion system-dependent mechanism ${ }^{49,50}$.

Thus, these mediators of inflammation form a complex of regulatory networks, and appear to work in concert to enhance cancer development. However, for normal cells to be eventually transformed and become cancer cells with clonal expansion, inflammation has to damage cellular DNA, either genetically or epigenetically, leading to permanent alteration within the genome. 


\section{Inflammation and Genetic Modulation}

Cancer is a genetic disease resulting from stepwise accumulation of genetic and epigenetic alterations that drives the progressive transformation of normal cells into malignant derivatives ${ }^{51}$. Inactivation of tumor-suppressor genes and/or activation of oncogenes caused by somatic mutations, DNA copy number changes, or chromosomal aberrations are widely detectable in human cancer cells. Among them, the tumor suppressor TP53 gene is one of the most frequent targets for genetic alterations in many human cancers ${ }^{52}$. An important point to note is that TP53 mutations are frequently present also in non-cancerous tissues with chronic inflammation before cancer development. Indeed, multiple genetic changes in the TP53 gene have been detected in various inflammatory tissues such as $\mathrm{IBD}^{53}, 54$, Barrett's esophagus ${ }^{55}$ and $\mathrm{HCV}$-associated chronic hepatitis ${ }^{56}$. For example, by analyzing the individual crypt mutation burden across plaques of the dysplasia, it was shown that mutations in TP53 genes could be identified in the majority of inflamed crypts of patients with ulcerative colitis (UC) ${ }^{57}$. Moreover, TP53 mutations are detectable at the frequencies of 4-15 nucleotides out of $10^{4}$ nucleotides in the hepatocytes of the patients with chronic HCV infecction $^{56}$. Normal mutation rates cannot account for such abundant genetic changes that accumulate in inflamed epithelial cells, suggesting that certain molecular mechanisms underlie such a large number of genetic alterations. Therefore, to understand the mechanisms of inflammation-associated tumorigenesis, several possible intrinsic mutagens responsible for genetic aberrations in the inflammatory condition have been proposed. Among them, free radicals and intrinsic DNA mutator enzymes appear to be important candidates in the setting of chronic inflammation (Figure 1).

Free radicals refer to any molecular species with one or more unpaired electron(s), including ROS and $\mathrm{RNS}^{38}$. Interestingly, increases in TP53 gene mutations at codons 247 and 248 are paralleled by an enhanced expression of nitric oxide synthase (iNOS) in the inflamed lesions of the colonic tissues of patients with ulcerative colitis ${ }^{54}$. HCV infection also induces iNOS mRNA expression, thereby enhancing nitric oxide (NO) production, which in turn results in DNA breaks and enhanced mutation frequencies ${ }^{58}$. Moreover, an increased level of NO accelerated spontaneous tumor development, mostly lymphomas, in Trp53-deficient mouse model infected with Cryptosporidium parvum $^{59}$.

In the inflammatory condition, cellular ROS levels are substantially elevated, and nucleic acids exposed to ROS generate various modified bases such as oxidatively altered purines and pyrimidines ${ }^{60}$. These modified nucleic acids could induce the 
putative DNA damage, including single- or double-stranded DNA breaks, DNA intrastrand adducts, and DNA protein crosslinks ${ }^{61}$. In addition, ROS alters the mismatch repair function and allows mutations to accumulate in microsatellite sequences ${ }^{62}$. It has been well recognized that oncogene activation is capable of inducing genomic instability in precancerous lesions as well as cancer cells ${ }^{63}$. In this regard, ROS is also a a putative mediators that links excessive activity of oncogene products and DNA damage. For example, oncogene $c-M Y C$ overexpression results in DNA damage prior to the $\mathrm{S}$ phase in association with the ROS induction in normal human fibroblasts ${ }^{64}$. These findings suggested that the cumulative situation of ROS production, a condition of so-called oxidative stress, is involved in both the initiation and progression of inflammation-associated cancers through the induction of genetic instability.

Importantly, the typical mutation pattern induced by oxidative stress cannot account for a mutation signature observed in many human cancer tissues, particularly in inflammation-associated cancers. Among the oxidized nucleosides, one of the common products of free radical attack on DNA is 8-hydroxydeoxyguanine (8-OHdG), which is considered to be a biomarker of oxidative stress ${ }^{65}$. The typical pattern of nucleotide alterations induced by $8-\mathrm{OHdG}$ is guanine $(\mathrm{G}) /$ cytosine $(\mathrm{C})$ to thymine (T)/adenine (A) transversions, which have been observed in the RAS oncogene and TP53 tumor suppressor gene in lung and liver cancers ${ }^{66,67}$. However, recent genome wide analyses clearly demonstrated that G/C to T/A transversions account for a minor proportion of the total mutations identified in human cancer cells, and instead $\mathrm{C} / \mathrm{G}$ to T/A transitions are the most prevalent mutation pattern in various cancer tissues, including inflammation-associated cancers ${ }^{68}$. Thus, it appears reasonable to assume that there is an alternative mechanism that accounts for the most frequent mutational pattern, $\mathrm{C} / \mathrm{G}$ to $\mathrm{T} / \mathrm{A}$ transitions, detected in many human cancer tissues.

Recently, several human enzymes that are capable of inducing nucleotide alterations have been identified, providing a new avenue for understanding mutagenesis mechanisms ${ }^{69}$. Among them, activation-induced cytidine deaminase (AID) is a well defined molecule involved in DNA mutations in the human genome. Through its enzymatic activity, AID can deaminate $\mathrm{C}$ on target DNA to produce a uracil (U), and therefore turns a DNA C:G pair into a $\mathrm{U}: \mathrm{G}$ mismatch. When DNA replication starts before recognition by the repair system, a $U: G$ mismatch gives rise to $C / G$ to $T / A$ transition. Alternatively, recognition of a $\mathrm{U}: \mathrm{G}$ mismatch by uracil-DNA-glycosylase (UNG) or mutS homolog 2 (MSH2)/mutS homolog 6 (MSH6) heterodimer induces mutations in the U:G mismatch or at the nearby A:T site (Figure 2). As a result, AID can induce any type of mutations ${ }^{70}$. Under physiological conditions, AID contributes to 
generating antibody gene diversification in activated B lymphocytes by inducing somatic hypermutation and class switch recombination of immunoglobulin gene ${ }^{71}$. In sharp contrast to the favorable function of AID in the immune system, the role of AID in tumorigenesis through induction of genetic instability was first suggested in hematopoietic malignancies. A number of studies have demonstrated that increased AID expression in various neoplasms of the B lymphocytic lineage was associated with unfavorable mutations and chromosomal translocations ${ }^{72,73}$. For instance, AID has been shown to be responsible for the chromosomal breaks in $c-M Y C$ leading to a c-MYC/immunoglobulin $H(I G H)$ translocation in B cell lymphoma ${ }^{74}$. Moreover, AID induces breakpoint cluster region (BCR)-Abelson murine leukemia viral oncogene homolog 1 ( $A B L 1$ ) mutations leading to Imatinib resistance in chronic myeloid leukemia cells $^{75}$. Since the target of AID-mediated genotoxic effects was not restricted to immunoglobulin genes and a variety of other genes also received the AID-mediated mutations in $\mathrm{B}$ cells ${ }^{70}$, it was not surprising that aberrant upregulation of AID induced genetic alterations in various tumor-related genes, leading to the transformation of hematopoietic cells.

As described, activation of NF- $\kappa \mathrm{B}$ is induced in response to various inflammatory stimulations, and is deeply involved in multiple processes of cancer initiation and progression ${ }^{36}$. Interestingly, NF- $\kappa \mathrm{B}$ is a major transcription factor for AID in B cells that is activated through cluster of differentiation 40-TNF receptor superfamily member 5 (CD40) ligation by $\mathrm{T}$ cells ${ }^{76}$, suggesting that AID might link NF- $\kappa \mathrm{B}$ activation and genetic instability in non-lymphoid cells in the setting of inflammation. In agreement with this hypothesis, AID expression is induced in response to proinflammatory cytokine stimulation via the NF- $\kappa$ B-dependent pathway in various epithelial cells (Figure 3). In hepatocytes, AID expression is induced by TNF- $\alpha$ through the I- $\kappa \mathrm{B}$ kinase (IKK)-dependent NF- $\kappa \mathrm{B}$ signaling pathway ${ }^{77}$. Consistent with a previous finding that the $\mathrm{HCV}$ core protein triggers the activation of NF- $\kappa \mathrm{B}$ in hepatocytes ${ }^{78}$, the HCV core protein itself also up-regulates endogenous AID in cultured hepatocytes ${ }^{77}$. NF- $\kappa$ B-mediated induction of AID expression is not limited to hepatocytes. In human gastric epithelial cells, AID expression is induced by TNF- $\alpha$ stimulation via activation of NF- $\kappa \mathrm{B}$, but not detected in non-stimulated cells ${ }^{79}$. More interestingly, aberrant AID expression is induced by the infection of a pathogenic $H$. pylori strain, the cytotoxin-associated gene pathogenicity island (CagPAI)-positive strain that is capable of introducing bacterial virulence factors into the host cells through a type-IV secretion system and activating NF- $\kappa \mathrm{B}$, indicating that both bacterial factors introduced into epithelial cells and the inflammatory mediators such as TNF- $\alpha$ and IL-1 $\beta$ induced by 
H. pylori infection cooperatively promote aberrant AID expression in H. pylori-infected gastric mucosal cells. Similar to hepatocytes and gastric mucosal cells, TNF- $\alpha$ stimulation resulted in upregulation of endogenous AID in human colonic cells via the IKK-dependent NF- $\kappa$ B signaling pathway ${ }^{80}$. In addition, IL-4 and IL-13, which are involved in Th2 type immune response in IBD, induced aberrant AID expression in a signal transducer and activator of transcription 6 (STAT6)-dependent manner in human colonic epithelial cells ${ }^{80}$. Of note, IL-4 is known to induce AID also in B cells ${ }^{71}$.

Consistent with the in vitro analyses, aberrant AID expression is widely detectable in not only various inflammation-associated cancer tissues but also in a variety of inflamed epithelial tissues where tumorigenic risk is high, including chronic hepatitis and cirrhosis caused by $\mathrm{HCV}$ infection ${ }^{56}$, chronic gastritis caused by $H$. pylori infection ${ }^{79}, \mathrm{IBD}^{80}, \mathrm{PSC}^{81}$, and the columnar cell-lined Barrett's esophagus ${ }^{82}$.

The impact of AID expression in non-lymphoid epithelial cells was clarified using both in vivo and in vitro systems with aberrant AID expression. Constitutive and ubiquitous AID expression in transgenic mice induced lymphoma development via the accumulation of somatic mutations in various non-immunoglobulin genes, including the proto-oncogene $c-M y c^{83}$. More importantly, further phenotypic analyses revealed that AID transgenic mice also develop neoplasia in epithelial tissues, including lung, liver and stomach accompanied by the emergence of Trp53 mutations, indicating that aberrant AID expression in epithelial cells can induce genetic instability leading to cancer development ${ }^{83,}{ }^{84}$. It is widely recognized that the frequently mutated tumor-related genes differ among different cancers. For instance, nucleotide alterations in the $K-R A S$ are detectable in almost all human pancreatic cancers ${ }^{85}$, while it is relatively low in other human tumors. Similarly, the $c-M Y C$ is a frequent target for genetic alterations in human lung cancers, while its nucleotide alterations are rare in hepatocellular carcinoma ${ }^{86}$. However, the mechanisms underlying the accumulation of organ-specific genomic changes in oncogenic pathways are not well known. Interestingly, organ-specific changes in mutational profiles were observed in the epithelial tissues of the AID transgenic mice. Indeed, the $c-M y c$ gene was frequently mutated in non-cancerous tissue of the lung, while $K$-ras gene mutations were frequently detectable in gastric cancer developed in AID transgenic mice ${ }^{84}$. Thus, the organ-specific differences in the mutational profiles in AID transgenic mice suggest the possibility that the target preference of AID-induced mutagenesis in different tissues might contribute to the diversity of tissue-specific oncogenic pathways in various epithelial organs.

In vitro analyses using human cultured cells with constitutive AID expression 
revealed that TP53 mutations were frequently induced by AID genotoxic activity in hepatocytes, and gastric, colonic, and bile duct epithelial cells ${ }^{77,79-81}$. Similar to the TP53 gene, the cyclin-dependent kinase inhibitor $(C D K N)-2 B-C D K N 2 A$ locus was identified as a target for AID-mediated genotoxic activity. The CDKN2B-CDKN2A locus encodes the potent suppressor proteins, $\mathrm{p} 16^{\mathrm{INK} 4 \mathrm{a}}, \mathrm{p} 15^{\mathrm{INK} 4 \mathrm{~b}}$, and $\mathrm{p} 14^{\mathrm{ARF}}$, that regulate the activities of the retinoblastoma protein (RB) and the TP53 transcription factor. Aberrant AID expression preferentially induces somatic mutations at the $C D K N 2 B-C D K N 2 A$ locus in gastric epithelial cells and biliary cells ${ }^{81,87}$. Moreover, comparative genomic hybridization analysis clearly demonstrated that constitutive AID activation in cultured gastric epithelial cells caused submicroscopic deletions as represented by copy number losses of various chromosomal loci, especially at the $C D K N 2 B-C D K N 2 A$ locus at 9p21. Copy number reduction of $C d k n 2 b-C d k n 2 a$ was also seen in the gastric mucosa of AID transgenic mice ${ }^{87}$. In agreement with the preferential deletions at the $C D K N 2 B-C D K N 2 A$ locus in gastric epithelial cells by AID introduction, AID expression was required for inducing DNA single-strand breaks in the $C D K N 2 B$ gene in leukemia cells ${ }^{88}$, and furthermore, the deletion of the $C D K N 2 B-C D K N 2 A$ locus is frequently detectable in AID-expressing lymphoid blast crisis leukemia cells ${ }^{75}$. These findings suggest that AID can induce both mutations and deletions at the same gene locus, and moreover, that the representative tumor-suppressor genes, TP53 and $C D K N 2 B-C D K N 2 A$ may be common targets for AID-mediated genotoxic effects in various human tissues in the setting of inflammation.

Finally, a recent finding that a deficiency of endogenous AID reduced the incidence of both accumulation of somatic mutations in the Trp53 gene and the development of colitis-associated colorectal cancers further supports the critical role of AID in inflammation-associated cancer development via its ability to induce genetic alterations in tumor-related genes ${ }^{89}$.

\section{Inflammation and Epigenetic Modulation}

Epigenetic modifications are DNA-associated modifications that are inherited upon somatic cell replication, which include DNA methylation and histone modifications ${ }^{90}$. Coordinated changes of epigenetic modifications control development and tissue differentiation, and erasure of epigenetic modifications is involved in reprogramming. In somatic cells, DNA methylation is present in repetitive elements, $\mathrm{CpG}$-sparse regions, and in a very limited number of $\mathrm{CpG}$ islands ${ }^{91,92}$. DNA methylation of a $\mathrm{CpG}$ island in a promoter region causes silencing of its downstream gene, whether it is a protein-coding 
gene or a miRNA gene, by forming nucleosomes and thus possibly blocking access of RNA polymerase II to the promoter ${ }^{93,94}$. In contrast, DNA methylation of a gene body is often associated with increased gene expression ${ }^{91,95}$.

Histone modifications denote chemical modifications, such as acetylation, methylation, and ubiquitination of lysine and arginine residues of histones, mainly $\mathrm{H} 3$ and $\mathrm{H} 4$ but also $\mathrm{H} 2 \mathrm{~A}$ and $\mathrm{H}_{2} \mathrm{~B}^{93}$. Specific histone modifications, such as acetylation of histones $\mathrm{H} 3$ and $\mathrm{H} 4$ (H3Ac and $\mathrm{H} 4 \mathrm{Ac}$ ) and trimethylation of lysine 4 of histone $\mathrm{H} 3$ (H3K4 me3) are associated with active gene transcription. In contrast, di- and trimethylation of $\mathrm{H} 3$ lysine 9 ( $\mathrm{H} 3 \mathrm{~K} 9$ me2 and $\mathrm{H} 3 \mathrm{~K} 9$ me3) and trimethylation of $\mathrm{H} 3$ lysine 27 (H3K27 me3) are associated with gene repression. H3K9 me2 represses gene transcription in concert with DNA methylation, while H3K27 me3 works independently of DNA methylation ${ }^{96}$. Trimethylation of $\mathrm{H} 3$ lysine 36 (H3K36 me3) is considered to mark exonic regions of active genes. However, the mechanisms of how histone modifications are inherited upon somatic cell replication remains unclear ${ }^{97}$.

In cancer cells, the presence of regional hypermethylation and global hypomethylation has been described ${ }^{98,99}$. Regional hypermethylation refers to aberrant DNA methylation of promoter $\mathrm{CpG}$ islands physiologically kept unmethylated ${ }^{95,100}$. If aberrant methylation is induced in a promoter $\mathrm{CpG}$ island, it consistently induces silencing of its downstream gene ${ }^{90}$. Many tumor-suppressor genes that have promoter CpG islands, such as CDKN2A, mutL homolog 1 (MLH1), cadherin-1 (CDH1), and RAS-association domain family 1 , isoform A (RASSF1A), can be permanently inactivated by aberrant DNA methylation as drivers, that have significant roles in cancer development. At the same time, most of the aberrant DNA methylation of promoter CpG islands are considered to be passengers, that play no role in carcinogenesis ${ }^{14}$. Several hundreds to thousands of promoter $\mathrm{CpG}$ islands are aberrantly methylated in a cancer, and the number is too large for all of them to be drivers. Moreover, most of the genes methylated in cancers are not expressed in normal tissues ${ }^{101,102}$, and such genes are considered to be not involved in carcinogenesis. Global hypomethylation was shown to be causally involved in carcinogenesis by inducing genomic instability ${ }^{103}$. In addition, induction of $\mathrm{H} 3 \mathrm{~K} 27$ me3 is considered to be an alternative mechanism to induce gene silencing ${ }^{96}$, and aberrant $\mathrm{H} 3 \mathrm{~K} 27$ me3 was observed in promoter regions consisting of 200-600 genes ${ }^{96,104}$. Again, the number is very large, and most are expected to be passengers.

As inducers of aberrant DNA methylation, aging was first indicated ${ }^{105}$, and chronic inflammation was then suggested by the presence of aberrant DNA methylation of specific tumor-suppressor genes in non-cancerous colonic mucosae of patients with 
$\mathrm{IBD}^{106,107}$. Aberrant DNA methylation was present more frequently in liver tissues of patients with $\mathrm{HCC}$ than in those with metastatic liver tumors ${ }^{108}$. By measuring methylation levels of passenger genes in gastric mucosae of $H$. pylori-infected individuals, a very close association between $H$. pylori infection and high methylation levels in gastric mucosa was demonstrated ${ }^{15}$. Aberrant DNA methylation is particularly prominent in chronic inflammation-associated cancers, such as gastric cancer, HCCs, colitic cancer, cholangiocarcinoma, Barrett's cancer, and pancreatic cancer ${ }^{13}$. These findings strongly indicated that the major inducer of aberrant DNA methylation is chronic inflammation.

Levels of aberrant DNA methylation accumulated in normal-appearing tissues correlate with the risk of gastric, colon, breast, and renal cancers ${ }^{15,109-112}$. Such accumulation mainly involves passenger and driver genes to some extent, and is considered to form an epigenetic field for cancerization (epigenetic field defect) (Figure $4)^{113}$. Chronic inflammation-associated cancers are known to show multiple events, which can be explained by the presence of a field defect in normal-appearing tissues. Along with the accumulation of genetic alterations, an epigenetic field defect is deeply involved in the development of inflammation-associated cancers. The degree of epigenetic field defect can be easily measured using methylation levels of marker genes ${ }^{114}$, which are passenger genes in most cases and show relatively high methylation levels in predisposed tissues ${ }^{113}$.

Mechanistic studies, including cause and effect of accumulated aberrant DNA methylation and chronic inflammation, were conducted using animal models. When $H$. pylori-induced inflammation was suppressed by cyclosporine A in Mongolian gerbils, induction of aberrant DNA methylation was markedly suppressed, while the number of $H$. pylori in gastric mucosae was unaffected ${ }^{16}$. This indicated that inflammation, not $H$. pylori itself, is critical for induction of aberrant DNA methylation. Expression analysis of inflammation-related genes showed that expression levels of Illb, Nos, Tnf, and chemokine (C-X-C motif) ligand $2(\mathrm{Cxcl} 2)$ correlated with methylation levels in gastric mucosae. H. pylori-induced inflammation was capable of inducing aberrant DNA methylation, but not repeated induction of acute inflammation by ethanol or a high sodium concentration ${ }^{115}$. Ill $\beta, N o s 2$ and Tnf were specifically upregulated by the $H$. pylori-induced inflammation. Notably, in humans, a polymorphism of the ILIB promoter was associated with not only gastric cancer susceptibility ${ }^{35}$, but also the presence of the $\mathrm{CpG}$ island methylation phenotype in gastric cancers ${ }^{116}$.

Another animal model for methylation induction by chronic inflammation is mouse colitis induced by administration of dextran sulfate sodium (DSS) ${ }^{117}$. Aberrant DNA 
methylation of multiple genes occurred in DSS-induced colitis mucosae before induction of colon tumors, showing an epigenetic field ${ }^{118}$. The induction of aberrant DNA methylation was unaffected even in severe combined immunodeficiency (SCID) mice that lacked $\mathrm{T}$ and $\mathrm{B}$ cells, suggesting that infiltrated macrophages might be critical for methylation induction. Gene expression analysis in colonic mucosae in wild-type and SCID mice showed that expression levels of $I l 1 b, N o s$, and Ifng were associated with methylation induction in colonic mucosae. Taken together with the finding in the $H$. pylori-infected gerbils, infiltration of macrophages and resulting secretion of Il-1 $\beta$ and Tnf- $\alpha$ as well as production of active oxygen species are believed to be involved in induction of aberrant DNA methylation in epithelial cells (Figure 1).

Several in vitro studies have been conducted to examine inflammatory signals that lead to methylation induction in target cells. Treatment of insulinoma or blood cells with IL-1 $\beta$ or a NO donor induced methylation of endogenous genes by increasing activity of DNA methyltransferase(s) (DNMTs) ${ }^{119}$. IL-6 induces DNMT1 transcription by increasing its promoter activity and suppressing miR-148a and miR-152, both of which target DNMT1 ${ }^{120,121 .}$ Although some studies suggested that DNA methylation is induced by IL-1 $\beta$ or IL- 6 , the changes were marginal possibly because identification of appropriate target $\mathrm{CpG}$ islands was difficult and the levels of increase were too small to be detected by ordinary methods. Prostaglandin E2 treatment of cancer cell lines increased DNMT1 and DNMT3B expression, and induced DNA methylation of specific genes, which was also observed in vivo ${ }^{122}$.

In contrast to in vitro studies, mRNA expression levels of Dnmt1, Dnmt3A, and Dnmt3B were not increased in vivo, such as colonic mucosae with DSS-induced colitis ${ }^{16}$, and human gastric tissues with $H$. pylori infection ${ }^{123}$. In line with these in vivo findings, O'Hagan et al. recently showed in vitro that oxidative damage recruits complexes containing DNMTs, a histone deacetylase (sirtuin 1, SIRT1), and histone methyltransferase (enhancer of zeste homolog 2, EZH2) to damaged chromatin, and induces DNA methylation ${ }^{124}$. They also showed that, in $A p c^{\text {Min }}$ mice infected with an inflammation-inducing bacterium, Dnmt1 and Ezh2 are recruited to promoter CpG islands of untranscribed or minimally transcribed genes. Promoter $\mathrm{CpG}$ islands with H3K27 me3 and without RNA polymerase II are susceptible to DNA methylation induction $^{101,102}$.

Taken together, we can hypothesize a model for aberrant DNA methylation induction in vivo (Figure 5). Inflammatory signals mainly from macrophages, such as IL- $1 \beta$, TNF- $\alpha$, and IL- 6 , and oxidative stress, possibly produced by NO synthase, are likely to recruit a complex with DNMT1 and EZH2 to promoter $\mathrm{CpG}$ islands with 
H3K27 me3 flag and without protection by RNA polymerase II. Since DNA methylation is harmful to a gene, aberrant DNA methylation is likely to be induced only rarely and at scattered $\mathrm{CpG}$ sites within a $\mathrm{CpG}$ island (seeds of methylation) ${ }^{123}$. Most "seeds of methylation" are erased during cell replication, but can lead to dense methylation of a $\mathrm{CpG}$ island at very low frequencies ${ }^{125,126}$. If such dense methylation is induced in a promoter $\mathrm{CpG}$ island of a tumor-suppressor gene, the tissue becomes predisposed to carcinogenesis, and forms an epigenetic field defect.

In addition to aberrant DNA methylation of promoter $\mathrm{CpG}$ islands, cancer cells are characterized by global DNA hypomethylation as well as aberrant hypomethylation of oncogenes $^{99,}{ }^{127}$. Gastric mucosa infected by $H$. pylori displays global hypomethylation ${ }^{128}$. In this regard, it is interesting to note that AID has been recently shown to be involved in active DNA demethylation during fetal development ${ }^{129}$. Mechanistically, AID deaminates 5-methyl cytosine (5-mC) to yield T. This T would be subsequently removed by either of the T:G mismatch-specific glycosylases, thymidine DNA glycosylase or methyl-CpG binding domain protein 4 (MBD4). The resulting abasic site would then be replaced by an unmethylated $C$ via base excision repair processes, resulting in DNA demethylation. Notably, AID participates in active demethylation by 5-mC hydroxylase, ten-eleven translocation 1 (TET1), and subsequent gene expression in the dentate gyrus of adult mouse brain ${ }^{130}$. Thus, whether AID is involved in DNA demethylation during cancer development is an interesting topic for future studies ${ }^{131}$. The fact that AID targets the chromatin marked by $\mathrm{H} 3 \mathrm{~K} 4$ me3 histone modification $^{132}$, in contrast to preferential DNA methylation at promoter $\mathrm{CpG}$ islands with $\mathrm{H} 3 \mathrm{~K} 27$ me3 histone modification ${ }^{101,102}$, might suggest opposing mechanisms for induction of DNA methylation and demethylation.

\section{Inflammation and MicroRNA Modulation}

MicroRNAs (miRNAs) are short noncoding RNAs that regulate the expression of many target genes post-transcriptionally, and are thus involved in a variety of cellular functions. Recent studies have revealed that miRNAs have important roles in cancer development as either oncogenes or tumor suppressor genes by regulating various cancer-related proteins or mRNA expressions ${ }^{133,134}$. Indeed, cancer cells are associated with dysregulation of many miRNA expressions, which occurs through a variety of mechanisms, such as genetic changes, epigenetic regulation, or altered expression of transcription factors ${ }^{135}$. On the other hand, miRNA expression is also altered in inflammatory conditions, and such alterations in miRNA expression appear to play roles 
not only in controlling chronic inflammation, but also in promoting cancer development ${ }^{136,}{ }^{137}$. Many of the changes in miRNA expressions observed in inflammatory tissues are derived from immune cells that may participate in hematopoietic tumorigenesis ${ }^{138}$. However, recent reports have shown that inflammation also induces changes in cancer-related miRNAs in epithelial cells, suggesting a direct link between alteration of miRNA expressions and inflammation-associated cancer development ${ }^{139,140}$.

miRNA expressions in epithelial cells can be altered during inflammation through various mechanisms such as NF- $\kappa \mathrm{B}$ activation by toll-like receptors (TLRs) or cytokine stimulation and STAT3 phosphorylation by IL-6 or other cytokines ${ }^{139-143}$. Among those, several miRNAs are identified as tumor suppressor miRNAs. miR-7 targets not only Egfr but also latrophilin (Lphn2), brain abundant, membrane attached signal protein 1 (Baspl) and musculoaponeurotic fibrosarcoma oncogene homolog (Mafg), and thus is considered to be a tumor suppressor miRNA ${ }^{142}$. In a mouse model of inflammation-associated cancer development, expression of $m i R-7$ has been shown to be inhibited by activated macrophages in Helicobacter-infected gastritis mucosa, being involved in gastric cancer development, whereas it was increased in germ-free conditions $^{142}$. Lethal-7 (Let-7), consisting of 12 members, targets the RAS family and $c-M Y C^{144,145}$, and genomic locations of let-7 family members are frequently deleted in colon cancers and other solid cancers ${ }^{146}$. NF- $\kappa$ B activation enhances Lin28B transcription that causes posttranscriptional inhibition of $l e t 7$ family member expression, and let-7 directly inhibits IL-6 expression, a cytokine often produced in cancer cells. Thus, reduction of let-7 expression by NF- $\kappa \mathrm{B}$ activation appears to play a role in a positive feedback loop for NF- $\kappa$ B activation through an increase of IL-6 in cancer cells 147

$m i R-155$, a possible oncogenic miRNA, is involved in blood cell maturation, immune responses and autoimmune disorders, and high expression of miR-155 is associated with the development of myeloproliferative disorders ${ }^{148}$. Recent studies have revealed a direct link between elevation of miR-155 and tumor formation and development in gastric and colon cancers ${ }^{148,}{ }^{149}$. miR-155 expression is induced by NF$\kappa \mathrm{B}$, IFN- $\beta$ and TLR stimulation ${ }^{150}$, and thus enhanced by $H$. pylori and lipopolysaccharadie (LPS) treatment ${ }^{151}$. Recently, Croce et al. ${ }^{143}$ reported that TNF- $\alpha$ /LPS stimulation enhances miR-155 expression in association with an increased mutation rate. They also showed that $m i R-155$ targets mitosis inhibitor protein kinase 1 (WEE1), which blocks cell-cycle progression, and therefore reasoned that reduction of WEE1 by miR-155 allowed cell division to continue even in the presence of DNA 
damage, leading to enhanced mutation induction. In another study, they also demonstrated that miR-155 promotes gene mutations by down-regulating the core mismatch repair proteins, hMSH2, hMSH6 and hMLH $1^{152}$. Of particular interest are the recent reports showing that miR-155 negatively regulates AID in B cells. Teng et al. ${ }^{153}$ demonstrated that miR-155 is upregulated in B cells undergoing class-switch recombination, and regulates the germinal center reaction by modulating AID. Moreover, miR-155 has been suggested to inhibit $M Y C-I G H$ translocation by reducing AID mRNA and protein in B cells ${ }^{154}$. Thus, although an inhibitory effect of miR-155 on AID has not been examined in non-B cells, miR-155 may also have a tumor suppressor function in epithelial cells by inhibiting AID production.

A miRNA expression pattern distinct from normal colonic mucosa has been found in the colonic mucosa and colitic tumor of patients with IBD as well as mice with colonic inflammation, including upregulation of $m i R-21$ and $m i R-3^{155} \cdot m i R-21$ is one of the most highly expressed miRNAs in colonic tissues of patients with ulcerative colitis $^{155}$, and its expression is enhanced by LPS and IL-6 through STAT3 activation, targeting key regulators of cell proliferation and apoptosis such as phosphatase and tensin homolog (PTEN) and programmed cell death 4 (PDCD4) ${ }^{156}$. Olaru et al. ${ }^{157}$ recently demonstrated that in colitic cancer development $m i R-31$ expression increases in a stepwise fashion from IBD to cancer, and that $m i R-31$ directly targets regulating factor inhibiting hypoxia inducible factor 1 (FIH-1), decreasing its repressor activity for hypoxia-inducible factor 1 (HIF-1).

It is now evident that miRNAs exert various functions in inflammation-associated cancer development. However, alterations of miRNA expression observed in inflammatory tissues occur in both immune cells and epithelial cells. Accordingly, it is important to dissect miRNA changes in the two cell types, as the patterns of the miRNA changes are different between immune cells and epithelial cells. Further elucidation of the changes of miRNA expression, particularly in epithelial cells, will facilitate our understanding of the role of tumor-related miRNAs in inflammation-associated cancer development.

\section{Application to Cancer Prevention, Diagnostics, and Therapeutics}

In order to prevent inflammation-associated cancer development, it is crucial to cure or control inflammation. Indeed, it has been repeatedly demonstrated that long-term therapy with anti-inflammatory drugs resulted in fewer appearances of tumors $^{158}$. The best way to control chronic inflammation is, of course, to eliminate 
causative infections. In other cases unrelated to infection such as IBD and PSC, one approach is to block the action of key regulators of inflammation. In this regard, NF- $\kappa$ B or STAT3, and their activators TNF- $\alpha$ or IL-6, respectively, may be good targets for suppressing the inflammatory response. However, since treatment usually needs to be continued for long periods to control chronic inflammation, agents without serious side effects with lower costs should be developed. For this purpose, many natural agents derived from vegetables, fruits, spices, and their components have been tested. Among them, curcumin, derived from yellow spice turmeric (Curcuma longa) has been used for centuries, and has been shown to suppress NF- $\kappa$ B- as well as STAT3-regulated inflammation $^{159}$, and thus can be administered safely over the long-term ${ }^{160}$. Indeed, a recent study showed that curcumin reduced TNF- $\alpha$ expression, prevented cancer-associated weight loss, and induced apoptosis of tumors in patients with colorectal cancer ${ }^{161}$. Resveratrol, a natural polyphenolic, non-flavonoid antioxidant found in grapes and other berries has been shown to have generalized inhibitory effects on inflammation-related molecules such as NF- $\kappa \mathrm{B}, \mathrm{COX} 2$ and tyrosine kinases ${ }^{162}$. Recently, Resveratrol was found to alter the expression of many tumor-related miRNAs ${ }^{163}$. Similar types of agents may have the potential to both prevent and treat cancers $^{164}$.

In contrast to controlling inflammatory mediators, blocking genetic modulation appears to be difficult. One might consider inhibiting AID. However, because AID plays a critical role in immunoglobulin maturation in B cells, specific targeting for AID in the epithelial cells without affecting AID in B cells is critical. Control of epigenetic modulation can be considered from two aspects: suppression of methylation induction and reversal of induced methylation. Since induction of methylation is not essential in adult somatic cells, control of this process is a promising approach to prevent chronic inflammation-associated cancers. On the other hand, reversal of aberrant DNA methylation is an attractive idea to repair an epigenetic field defect, but targeting only aberrant DNA methylation without affecting physiological DNA methylation is currently very difficult.

H. pylori eradication ameliorates chronic inflammation, and reduces the risk for gastric cancer. However, it is apparent that eradication cannot completely resolve chronic inflammation, as some patients develop gastric cancer even after successful eradication $^{165}$. Likewise, some patients with chronic hepatitis or liver cirrhosis due to $\mathrm{HCV}$ infection also develop $\mathrm{HCC}$ after obtaining sustained virological response $(\mathrm{SVR})^{166}$. As such, when inflammation is not appropriately controlled or even when inflammation is resolved after long-standing inflammation, accurate prediction for the 
risk of developing cancers in the inflammatory tissues becomes important. As was discussed, carcinogenesis is characterized by a stepwise accumulation of both genetic and epigenetic changes. Importantly, previous data suggested that the extent of those genetic and epigenetic modulations is paralleled with duration or severity of inflammation $^{15,167}$, and the degree of epigenetic field defect can be measured relatively easily and accurately. Thus, both qualitative and quantitative detection of these genetic and epigenetic changes in inflammatory tissues or tissues previously exposed to inflammation may provide a good risk marker for inflammation-associated cancer development. Indeed, epigenetic risk markers that can differentiate gastric mucosae of cancer patients from those of healthy individuals with odds ratios between 12.7-36.0 have been isolated ${ }^{168,169}$, and a prospective study is now being conducted.

\section{Conclusion}

Many cancers in digestive organs develop in the background of chronic inflammation. During chronic inflammation, a variety of mediators for inflammation such as cytokines, growth factors, eicosanoids, ROS and NOS form complex networks for not only maintaining or reducing inflammation but also promoting cell growth, angiogenesis and inhibiting apoptosis. These events eventually merge into and result in both genetic and epigenetic changes of the cellular genome, leading to inflammation-associated cancer development. In particular, AID plays a crucial role in inducing not only mutations, but also chromosomal aberrations during inflammation. Moreover, signals from macrophages with resulting mislocalization of DNMTs appear to be involved in the induction of epigenetic alterations.

Interestingly, epigenetic inactivation of $M L H 1$ leads to accumulation of genetic alterations $^{170}$. At the same time, recent studies have demonstrated that AID induces DNA demethylation through its deaminating activity on methylated cytosines ${ }^{131}$. Thus, genetic and epigenetic events are mutually related and work in concert in the development of inflammation-associated cancers. 


\section{References}

1. Coussens LM, Werb Z. Inflammation and cancer. Nature 2002;420:860-867.

2. Walczak H. TNF and ubiquitin at the crossroads of gene activation, cell death, inflammation, and cancer. Immunol Rev 2011;244:9-28.

3. Yeh JM, Goldie SJ, Kuntz KM, et al. Effects of Helicobacter pylori infection and smoking on gastric cancer incidence in China: a population-level analysis of trends and projections. Cancer Causes Control 2009;20:2021-2029.

4. Vennervald BJ, Polman K. Helminths and malignancy. Parasite Immunol 2009;31:686-696.

5. Balkwill F, Mantovani A. Inflammation and cancer: back to Virchow? Lancet 2001;357:539-545.

6. Hussain SP, Harris CC. Inflammation and cancer: an ancient link with novel potentials. Int J Cancer 2007;121:2373-2380.

7. Mantovani A, Allavena P, Sica A, et al. Cancer-related inflammation. Nature 2008;454:436-444.

8. Stephens PJ, McBride DJ, Lin ML, et al. Complex landscapes of somatic rearrangement in human breast cancer genomes. Nature 2009;462:1005-1010.

9. Pleasance ED, Stephens PJ, O'Meara S, et al. A small-cell lung cancer genome with complex signatures of tobacco exposure. Nature 2010;463:184-190.

10. Sjoblom T, Jones S, Wood LD, et al. The consensus coding sequences of human breast and colorectal cancers. Science 2006;314:268-274.

11. Pleasance ED, Cheetham RK, Stephens PJ, et al. A comprehensive catalogue of somatic mutations from a human cancer genome. Nature 2010;463:191-196.

12. Kumar-Sinha C, Tomlins SA, Chinnaiyan AM. Recurrent gene fusions in prostate cancer. Nat Rev Cancer 2008;8:497-511.

13. Ushijima T, Hattori N. Molecular Pathways: Involvement of Helicobacter pylori-Triggered Inflammation in the Formation of an Epigenetic Field Defect, and Its Usefulness as Cancer Risk and Exposure Markers. Clin Cancer Res 2012;18:923-929.

14. Ushijima T, Asada K. Aberrant DNA methylation in contrast with mutations. Cancer Sci 2010;101:300-305.

15. Maekita T, Nakazawa K, Mihara M, et al. High levels of aberrant DNA methylation in Helicobacter pylori-infected gastric mucosae and its possible association with gastric cancer risk. Clin Cancer Res 2006;12:989-995.

16. Niwa $\mathrm{T}$, Tsukamoto $\mathrm{T}$, Toyoda $\mathrm{T}$, et al. Inflammatory processes triggered by 
Helicobacter pylori infection cause aberrant DNA methylation in gastric epithelial cells. Cancer Res 2010;70:1430-1440.

17. Jemal A, Bray F, Center MM, et al. Global cancer statistics. CA Cancer J Clin 2011;61:69-90.

18. Altekruse SF, McGlynn KA, Reichman ME. Hepatocellular carcinoma incidence, mortality, and survival trends in the United States from 1975 to 2005. J Clin Oncol 2009;27:1485-1491.

19. Warren JR, Marshall B. Unidentified curved bacilli on gastric epithelium in active chronic gastritis. Lancet 1983;1:1273-1275.

20. Uemura N, Okamoto S, Yamamoto S, et al. Helicobacter pylori infection and the development of gastric cancer. N Engl J Med 2001;345:784-789.

21. Chiba T, Marusawa H, Seno H, et al. Mechanism for gastric cancer development by Helicobacter pylori infection. J Gastroenterol Hepatol 2008;23:1175-1181.

22. Parkin DM. The global health burden of infection-associated cancers in the year 2002. Int J Cancer 2006;118:3030-3044.

23. Bernstein CN, Blanchard JF, Kliewer E, et al. Cancer risk in patients with inflammatory bowel disease: a population-based study. Cancer 2001;91:854-862.

24. Askling J, Linet M, Gridley G, et al. Cancer incidence in a population-based cohort of individuals hospitalized with celiac disease or dermatitis herpetiformis. Gastroenterology 2002;123:1428-1435.

25. Elfstrom P, Granath F, Ye W, et al. Low risk of gastrointestinal cancer among patients with celiac disease, inflammation, or latent celiac disease. Clin Gastroenterol Hepatol 2012;10:30-36.

26. Patel T. Cholangiocarcinoma. Nat Clin Pract Gastroenterol Hepatol 2006;3:33-42.

27. Imam MH, Silveira MG, Sinakos E, et al. Long-term Outcomes of Patients With Primary Biliary Cirrhosis and Hepatocellular Carcinoma. Clin Gastroenterol Hepatol 2012;10:182-185.

28. Shaheen NJ, Richter JE. Barrett's oesophagus. Lancet 2009;373:850-861.

29. DiMagno EP, Reber HA, Tempero MA. AGA technical review on the epidemiology, diagnosis, and treatment of pancreatic ductal adenocarcinoma. American Gastroenterological Association. Gastroenterology 1999; 117: 14641484 .

30. Whitcomb DC, Applebaum S, Martin SP. Hereditary pancreatitis and pancreatic carcinoma. Ann N Y Acad Sci 1999;880:201-209.

31. Wotherspoon AC, Doglioni C, Diss TC, et al. Regression of promary low-grade B 
cell gastric lymphoma of mucosa-associated lymphoid tissue type after eradication of Helicobacter pylori. Lancet 1993;342:575-577.

32. Kodama Y, Kawabata K, Yoshida S, et al. Malt lymphoma simulating an extramedullary plasmacytoma of the stomach. Am J Med 1999;107:530-532.

33. Hartridge-Lambert SK, Stein EM, Markowitz AJ, et al. Hepatitis C and non-hodgkin lymphoma: The clinical perspective. Hepatology 2012;55:634-641.

34. Smedby KE, Akerman M, Hildebrand H, et al. Malignant lymphomas in coeliac disease: evidence of increased risks for lymphoma types other than enteropathy-type T cell lymphoma. Gut 2005;54:54-59.

35. El-Omar EM, Carrington M, Chow WH, et al. Interleukin-1 polymorphisms associated with increased risk of gastric cancer. Nature 2000;404:398-402.

36. Ben-Neriah Y, Karin M. Inflammation meets cancer, with NF-kappaB as the matchmaker. Nat Immunol 2011;12:715-723.

37. Kuraishy A, Karin M, Grivennikov SI. Tumor promotion via injury- and death-induced inflammation. Immunity 2011;35:467-477.

38. Hussain SP, Hofseth LJ, Harris CC. Radical causes of cancer. Nat Rev Cancer 2003;3:276-285.

39. Wang D, DuBois RN. Eicosanoids and cancer. Nat Rev Cancer 2010;10:181-193.

40. Ziech D, Franco R, Pappa A, et al. Reactive oxygen species (ROS)--induced genetic and epigenetic alterations in human carcinogenesis. Mutat Res 2011;711:167-173.

41. Sekikawa A, Fukui H, Fujii $S$, et al. REG Ialpha protein mediates an anti-apoptotic effect of STAT3 signaling in gastric cancer cells. Carcinogenesis 2008;29:76-83.

42. Kanda K, Komekado H, Sawabu T, et al. Nardilysin and ADAM proteases promote gastric cancer cell growth by activating intrinsic cytokine signalling via enhanced ectodomain shedding of TNF-alpha. EMBO Mol Med 2012;4:396-411.

43. Schievella AR, Chen JH, Graham JR, et al. MADD, a novel death domain protein that interacts with the type I tumor necrosis factor receptor and activates mitogen-activated protein kinase. J Biol Chem 1997;272:12069-12075.

44. Kamimura D, Ishihara K, Hirano T. IL6-signal transduction and its physiological roles: the signal orchestration model. Rev Physiol Biochem Pharmacol 2003;149:1-38.

45. Chen F. JNK-induced apoptosis, compensatory growth, and cancer stem cells. 
Cancer Res 2012;72:379-386.

46. Liu J, Yan J, Jiang S, et al. Site-specific ubiquitination is required for releaving the transcription factor Miz1-mediated suppresion on TNF $\alpha$-induced JNK activation and inflammation. Proc Natl Acad Sci 2012;109:191-196.

47. Inokuchi S, Aoyama T, Miura K, et al. Disruption of TAK1 in hepatocytes causes hepatic injury, inflammation, fibrosis and carcinogenesis. Proc Natl Acad Sci USA 2010;107:844-849.

48. Chang Q, Zhang Y, Beezhold KJ, et al. Sustained JNK1 activation is associated with altered histone H3 methylations in human liver cancer. J Hepatol 2009; 50: 323-333.

49. Higashi H, Tsutsumi R, Muto S, et al. SHP-2 tyrosine phosphatase as an intracellular target of Helicobacter pylori CagA protein. Science 2002;295:683-686.

50. Snider JL, Allison C, Bellaire $\mathrm{BH}$, et al. The beta1 integrin activates JNK independent of CagA, and JNK actvation is required for Helicobacter pylori CagA+-induced motility of gastric cancer cells. J Biol Chem 2008; 283: 13952-13963.

51. Hanahan D, Weinberg RA. The hallmarks of cancer. Cell 2000;100:57-70.

52. Joerger AC, Fersht AR. Structure-function-rescue: the diverse nature of common p53 cancer mutants. Oncogene 2007;26:2226-2242.

53. Brentnall TA, Haggitt RC, Rabinovitch PS, et al. Risk and natural history of colonic neoplasia in patients with primary sclerosing cholangitis and ulcerative colitis. Gastroenterology 1996;110:331-338.

54. Hussain SP, Amstad P, Raja K, et al. Increased p53 mutation load in noncancerous colon tissue from ulcerative colitis: a cancer-prone chronic inflammatory disease. Cancer Res 2000;60:3333-3337.

55. Barrett MT, Sanchez CA, Prevo LJ, et al. Evolution of neoplastic cell lineages in Barrett oesophagus. Nat Genet 1999;22:106-109.

56. Kou T, Marusawa H, Kinoshita K, et al. Expression of activation-induced cytidine deaminase in human hepatocytes during hepatocarcinogenesis. Int $\mathbf{J}$ Cancer 2007;120:469-476.

57. Leedham SJ, Graham TA, Oukrif D, et al. Clonality, founder mutations, and field cancerization in human ulcerative colitis-associated neoplasia. Gastroenterology 2009; 136:542-550.

58. Machida K, Cheng KT, Sung VM, et al. Hepatitis $\mathrm{C}$ virus infection activates the immunologic (type II) isoform of nitric oxide synthase and thereby enhances 
DNA damage and mutations of cellular genes. J Virol 2004;78:8835-8843.

59. Hussain SP, He P, Subleski J, et al. Nitric oxide is a key component in inflammation-accelerated tumorigenesis. Cancer Res 2008;68:7130-7136.

60. Demple B, Harrison L. Repair of oxidative damage to DNA: enzymology and biology. Annu Rev Biochem 1994;63:915-948.

61. Federico A, Morgillo F, Tuccillo C, et al. Chronic inflammation and oxidative stress in human carcinogenesis. Int J Cancer 2007;121:2381-2386.

62. Gasche C, Chang CL, Rhees J, et al. Oxidative stress increases frameshift mutations in human colorectal cancer cells. Cancer Res 2001;61:7444-7448.

63. Halazonetis TD, Gorgoulis VG, Bartek J. An oncogene-induced DNA damage model for cancer development. Science 2008;319:1352-1355.

64. Vafa O, Wade M, Kern S, et al. c-Myc can induce DNA damage, increase reactive oxygen species, and mitigate p53 function: a mechanism for oncogene-induced genetic instability. Mol Cell 2002;9:1031-1044.

65. Evans MD, Dizdaroglu M, Cooke MS. Oxidative DNA damage and disease: induction, repair and significance. Mutat Res 2004;567:1-61.

66. Takahashi T, Nau MM, Chiba I, et al. p53: a frequent target for genetic abnormalities in lung cancer. Science 1989;246:491-494.

67. Hsu IC, Metcalf RA, Sun T, et al. Mutational hotspot in the p53 gene in human hepatocellular carcinomas. Nature 1991;350:427-428.

68. Greenman C, Stephens P, Smith R, et al. Patterns of somatic mutation in human cancer genomes. Nature 2007;446:153-158.

69. Conticello SG. The AID/APOBEC family of nucleic acid mutators. Genome Biol 2008;9:229 (1-10).

70. Liu M, Duke JL, Richter DJ, et al. Two levels of protection for the B cell genome during somatic hypermutation. Nature 2008;451:841-845.

71. Honjo T, Kinoshita K, Muramatsu M. Molecular mechanism of class switch recombination: linkage with somatic hypermutation. Annu Rev Immunol 2002;20:165-196.

72. Greeve J, Philipsen A, Krause K, et al. Expression of activation-induced cytidine deaminase in human B-cell non-Hodgkin lymphomas. Blood 2003;101:3574-3580.

73. Pasqualucci L, Guglielmino R, Houldsworth J, et al. Expression of the AID protein in normal and neoplastic B cells. Blood 2004;104:3318-3325.

74. Robbiani DF, Bothmer A, Callen E, et al. AID is required for the chromosomal breaks in $c-m y c$ that lead to $c-m y c / I g H$ translocations. Cell 2008;135:1028-1038. 
75. Klemm L, Duy C, Iacobucci I, et al. The B cell mutator AID promotes B lymphoid blast crisis and drug resistance in chronic myeloid leukemia. Cancer Cell 2009;16:232-245.

76. Nagaoka H, Tran TH, Kobayashi M, et al. Preventing AID, a physiological mutator, from deleterious activation: regulation of the genomic instability that is associated with antibody diversity. Int Immunol 2010;22:227-235.

77. Endo Y, Marusawa H, Kinoshita K, et al. Expression of activation-induced cytidine deaminase in human hepatocytes via NF-kappaB signaling. Oncogene 2007;26:5587-5595.

78. Marusawa H, Hijikata M, Chiba T, et al. Hepatitis $\mathrm{C}$ virus core protein inhibits Fas- and tumor necrosis factor alpha-mediated apoptosis via NF-kappaB activation. J Virol 1999;73:4713-4720.

79. Matsumoto Y, Marusawa H, Kinoshita K, et al. Helicobacter pylori infection triggers aberrant expression of activation-induced cytidine deaminase in gastric epithelium. Nat Med 2007;13:470-476.

80. Endo Y, Marusawa H, Kou T, et al. Activation-induced cytidine deaminase links between inflammation and the development of colitis-associated colorectal cancers. Gastroenterology 2008;135:889-898.

81. Komori J, Marusawa H, Machimoto $\mathrm{T}$, et al. Activation-induced cytidine deaminase links bile duct inflammation to human cholangiocarcinoma. Hepatology 2008;47:888-896.

82. Morita S, Matsumoto Y, Okuyama S, et al. Bile acid-induced expression of activation-induced cytidine deaminase during the development of Barrett's oesophageal adenocarcinoma. Carcinogenesis 2011;32:1706-1712.

83. Okazaki IM, Hiai H, Kakazu N, et al. Constitutive expression of AID leads to tumorigenesis. J Exp Med 2003;197:1173-1181.

84. Morisawa T, Marusawa H, Ueda Y, et al. Organ-specific profiles of genetic changes in cancers caused by activation-induced cytidine deaminase expression. Int J Cancer 2008;123:2735-2740.

85. Almoguera C, Shibata D, Forrester K, et al. Most human carcinomas of the exocrine pancreas contain mutant c-K-ras genes. Cell 1988;53:549-554.

86. Thorgeirsson SS, Grisham JW. Molecular pathogenesis of human hepatocellular carcinoma. Nat Genet 2002;31:339-346.

87. Matsumoto Y, Marusawa H, Kinoshita K, et al. Up-regulation of activation-induced cytidine deaminase causes genetic aberrations at the CDKN2b-CDKN2a in gastric cancer. Gastroenterology 2010;139:1984-1994. 
88. Feldhahn N, Henke N, Melchior K, et al. Activation-induced cytidine deaminase acts as a mutator in BCR-ABL1-transformed acute lymphoblastic leukemia cells. J Exp Med 2007;204:1157-1166.

89. Takai A, Marusawa H, Minaki Y, et al. Targeting activation-induced cytidine deaminase prevents colon cancer development despite persistent colonic inflammation. Oncogene 2012;31:1733-1742.

90. Jones PA, Baylin SB. The epigenomics of cancer. Cell 2007;128:683-692.

91. Rauch TA, Wu X, Zhong X, et al. A human B cell methylome at 100-base pair resolution. Proc Natl Acad Sci USA 2009;106:671-678.

92. Lister R, Pelizzola M, Dowen RH, et al. Human DNA methylomes at base resolution show widespread epigenomic differences. Nature 2009;462:315-322.

93. Li B, Carey M, Workman JL. The role of chromatin during transcription. Cell 2007;128:707-719.

94. Lin JC, Jeong S, Liang G, et al. Role of nucleosomal occupancy in the epigenetic silencing of the MLH1 CpG island. Cancer Cell 2007;12:432-444.

95. Yamashita S, Hosoya K, Gyobu K, et al. Development of a novel output value for quantitative assessment in methylated DNA immunoprecipitation-CpG island microarray analysis. DNA Res 2009;16:275-286.

96. Kondo Y, Shen L, Cheng AS, et al. Gene silencing in cancer by histone H3 lysine 27 trimethylation independent of promoter DNA methylation. Nat Genet 2008;40:741-750.

97. Margueron R, Reinberg D. Chromatin structure and the inheritance of epigenetic information. Nat Rev Genet 2010;11:285-296.

98. Feinberg AP, Tycko B. The history of cancer epigenetics. Nat Rev Cancer 2004;4:143-153.

99. Yoshida T, Yamashita S, Takamura-Enya T, et al. Alu and Sat $\alpha$ hypomethylation in Helicobacter pylori-infected gastric mucosae. Int J Cancer 2011;128:33-39.

100. Rauch TA, Zhong $\mathrm{X}$, Wu $\mathrm{X}$, et al. High-resolution mapping of DNA hypermethylation and hypomethylation in lung cancer. Proc Natl Acad Sci USA 2008;105:252-257.

101. Takeshima H, Ushijima T. Methylation destiny: Moira takes account of histones and RNA polymerase II. Epigenetics 2010;5:89-95.

102. Takeshima H, Yamashita S, Shimazu T, et al. The presence of RNA polymerase II, active or stalled, predicts epigenetic fate of promoter $\mathrm{CpG}$ islands. Genome Res 2009;19:1974-1982.

103. Chen RZ, Pettersson U, Beard C, et al. DNA hypomethylation leads to elevated 
mutation rates. Nature 1998;395:89-93.

104. Enroth S, Rada-Iglesisas A, Andersson R, et al. Cancer associated epigenetic transitions identified by genome-wide histone methylation binding profiles in human colorectal cancer samples and paired normal mucosa. BMC cancer 2011;11:450.

105. Issa JP, Ottaviano YL, Celano P, et al. Methylation of the oestrogen receptor $\mathrm{CpG}$ island links ageing and neoplasia in human colon. Nat Genet 1994;7:536-540.

106. Hsieh CJ, Klump B, Holzmann K, et al. Hypermethylation of the p16INK4a promoter in colectomy specimens of patients with long-standing and extensive ulcerative colitis. Cancer Res 1998;58:3942-3945.

107. Issa JP, Ahuja $\mathrm{N}$, Toyota $\mathrm{M}$, et al. Accelerated age-related $\mathrm{CpG}$ island methylation in ulcerative colitis. Cancer Res 2001;61:3573-3577.

108. Kondo Y, Kanai Y, Sakamoto M, et al. Genetic instability and aberrant DNA methylation in chronic hepatitis and cirrhosis--A comprehensive study of loss of heterozygosity and microsatellite instability at 39 loci and DNA hypermethylation on $8 \mathrm{CpG}$ islands in microdissected specimens from patients with hepatocellular carcinoma. Hepatology 2000;32:970-979.

109. Nakajima T, Maekita T, Oda I, et al. Higher methylation levels in gastric mucosae significantly correlate with higher risk of gastric cancers. Cancer Epidemiol Biomarkers Prev 2006;15:2317-2321.

110. Shen L, Kondo Y, Rosner GL, et al. MGMT promoter methylation and field defect in sporadic colorectal cancer. J Natl Cancer Inst 2005;97:1330-1338.

111. Yan PS, Venkataramu C, Ibrahim A, et al. Mapping geographic zones of cancer risk with epigenetic biomarkers in normal breast tissue. Clin Cancer Res 2006;12:6626-6636.

112. Arai E, Kanai Y, Ushijima S, et al. Regional DNA hypermethylation and DNA methyltransferase (DNMT) 1 protein overexpression in both renal tumors and corresponding nontumorous renal tissues. Int J Cancer 2006;119:288-296.

113. Ushijima T. Epigenetic field for cancerization. $\mathrm{J}$ Biochem Mol Biol 2007;40:142-150.

114. Shin CM, Kim N, Park JH, et al. Prediction of the risk for gastric ancer using candidate methylation markers in the non-neoplastic gastric mucosae. J Pathol 2012;226:654-665.

115. Hur K, Niwa T, Toyoda T, et al. Insufficient role of cell proliferation in aberrant DNA methylation induction and involvement of specific types of inflammation. 
Carcinogenesis 2011;32:35-41.

116. Yoo EJ, Park SY, Cho NY, et al. Influence of IL1B polymorphism on CpG island hypermethylation in Helicobacter pylori-infected gastric cancer. Virchows Arch 2010;456:647-652.

117. Rosenberg DW, Giardina C, Tanaka T. Mouse models for the study of colon carcinogenesis. Carcinogenesis 2009;30:183-196.

118. Katsurano M, Niwa T, Yasui Y, et al. Early-stage formation of an epigenetic field defect in a mouse colitis model, and non-essential roles of T- and B-cells in DNA methylation induction. Oncogene 2012;31:342-351.

119. Hmadcha A, Bedoya FJ, Sobrino F, et al. Methylation-dependent gene silencing induced by interleukin lbeta via nitric oxide production. J Exp Med 1999;190:1595-1604.

120. Hodge DR, Xiao W, Clausen PA, et al. Interleukin-6 regulation of the human DNA methyltransferase (HDNMT) gene in human erythroleukemia cells. J Mol Biol 2001;276:39508-39511.

121. Braconi C, Huang N, Patel T. MicroRNA-dependent regulation of DNA methyltransferase- 1 and tumor suppressor gene expression by interleukin- 6 in human malignant cholangiocytes. Hepatology 2010;51:881-890.

122. Xia D, Wang D, Kim SH, et al. Prostaglandin E(2) promotes intestinal tumor growth via DNA methylation. Nat Med 2012;18:224-226.

123. Nakajima $T$, Yamashita $S$, Maekita $T$, et al. The presence of a methylation fingerprint of Helicobacter pylori infection in human gastric mucosae. Int $\mathbf{J}$ Cancer 2009;124:905-910.

124. O'Hagan HM, Wang W, Sen S, et al. Oxidative damage targets complexes containing DNA methyltransferases, SIRT1, and polycomb members to promoter CpG Islands. Cancer Cell 2011;20:606-619.

125. Stirzaker C, Song JZ, Davidson B, et al. Transcriptional gene silencing promotes DNA hypermethylation through a sequential change in chromatin modifications in cancer cells. Cancer Res 2004;64:3871-3877.

126. Ushijima T, Watanabe N, Shimizu K, et al. Decreased fidelity in replicating CpG methylation patterns in cancer cells. Cancer Res 2005;65:11-17.

127. Ehrlich M. DNA hypomethylation in cancer cells. Epigenomics 2009;1:239-259.

128. Bae JM, Shin SH, Kwon HJ, et al. ALU and LINE-1 hypomethylations in multistep gastric carcinogenesis and their prognostic implications. Int J Cancer 2012 (in press)

129. Cortellino S, Xu J, Sannai M, et al. Thymine DNA glycosylase is essential for 
active DNA demethylation by linked deamination-base excision repair. Cell 2011;146:67-79.

130. Guo JU, Su Y, Zhong C, et al. Hydroxylation of 5-methylcytosine by TET1 promotes active DNA demethylation in the adult brain. Cell 2011;145:423-434.

131. Fritz EL, Papavasiliou N. Cytidine deaminases: AIDing DNA demethylation? Genes Dev 2010;24:2107-2114.

132. Kato L, Begum NA, Burroughs AM, et al. Nonimmunoglobulin target loci of activation-induced cytidine deaminase (AID) share unique features with immunoglobulin genes. Proc Natl Acad Sci USA 2012;109:2479-2484.

133. Di Leva G, Croce CM. Roles of small RNAs in tumor formation. Trends Mol Med 2010;16:257-267.

134. Croce CM. Causes and consequences of microRNA dysregulation in cancer. Nat Rev Genet 2009;10:704-714.

135. Lu J, Getz G, Miska EA, et al. MicroRNA expression profiles classify human cancers. Nature 2005;435:834-838.

136. Sonkoly E, Pivarcsi A. MicroRNAs in inflammation and response to injuries induced by environmental pollution. Mutat Res 2011;717:46-53.

137. O'Connell RM, Rao DS, Baltimore D. MicroRNA Regulation of Inflammatory Responses. Annu Rev Immunol 2012;30:295-312.

138. Zhao JL, Rao DS, Boldin MP, et al. NF-kappaB dysregulation in microRNA-146a-deficient mice drives the development of myeloid malignancies. Proc Natl Acad Sci USA 2011;108:9184-9189.

139. Padgett KA, Lan RY, Leung PC, et al. Primary biliary cirrhosis is associated with altered hepatic microRNA expression. J Autoimmun 2009;32:246-253.

140. Wu F, Zikusoka M, Trindade A, et al. MicroRNAs are differentially expressed in ulcerative colitis and alter expression of macrophage inflammatory peptide-2 alpha. Gastroenterology 2008;135:1624-1635.

141. Schetter AJ, Heegaard NH, Harris CC. Inflammation and cancer: interweaving microRNA, free radical, cytokine and p53 pathways. Carcinogenesis 2010;31:37-49.

142. Kong D, Piao YS, Yamashita S, et al. Inflammation-induced repression of tumor suppressor miR-7 in gastric tumor cells. Oncogene 2011 Dec 5 [Epub ahead of print].

143. Tili E, Michaille JJ, Wernicke D, et al. Mutator activity induced by microRNA-155 (miR-155) links inflammation and cancer. Proc Natl Acad Sci USA 2011;108:4908-4913. 
144. Johnson SM, Grosshans H, Shingara J, et al. RAS is regulated by the let-7 microRNA family. Cell 2005;120:635-647.

145. Akao Y, Nakagawa Y, Naoe T. let-7 microRNA functions as a potential growth suppressor in human colon cancer cells. Biol Pharm Bull 2006;29:903-906.

146. Calin GA, Sevignani C, Dumitru CD, et al. Human microRNA genes are frequently located at fragile sites and genomic regions involved in cancers. Proc Natl Acad Sci USA 2004;101:2999-3004.

147. Iliopoulos D, Hirsch HA, Struhl K. An epigenetic switch involving NF-kappaB, Lin28, Let-7 MicroRNA, and IL6 links inflammation to cell transformation. Cell 2009;139:693-706.

148. Tili E, Croce CM, Michaille JJ. miR-155: on the crosstalk between inflammation and cancer. Int Rev Immunol 2009;28:264-284.

149. Volinia S, Calin GA, Liu CG, et al. A microRNA expression signature of human solid tumors defines cancer gene targets. Proc Natl Acad Sci USA 2006;103:2257-2261.

150. O'Connell RM, Taganov KD, Boldin MP, et al. MicroRNA-155 is induced during the macrophage inflammatory response. Proc Natl Acad Sci USA 2007;104:1604-1609.

151. Xiao B, Liu Z, Li BS, et al. Induction of microRNA-155 during Helicobacter pylori infection and its negative regulatory role in the inflammatory response. $\mathrm{J}$ Infect Dis 2009;200:916-925.

152. Valeri N, Gasparini P, Fabbri M, et al. Modulation of mismatch repair and genomic stability by miR-155. Proc Natl Acad Sci USA 2010;107:6982-6987.

153. Teng G, Hakimpour P, Landgraf P, et al. MicroRNA-155 is a negative regulator of activation-induced cytidine deaminase. Immunity 2008;28:621-629.

154. Dorsett Y, McBride KM, Jankovic M, et al. MicroRNA-155 suppresses activation-induced cytidine deaminase-mediated Myc-Igh translocation. Immunity 2008;28:630-638.

155. Pekow JR, Kwon JH. MicroRNAs in inflammatory bowel disease. Inflamm Bowel Dis 2012;18:187-193.

156. Iliopoulos D, Jaeger SA, Hirsch HA, et al. STAT3 activation of miR-21 and miR-181b-1 via PTEN and CYLD are part of the epigenetic switch linking inflammation to cancer. Mol Cell 2010;39:493-506.

157. Olaru AV, Selaru FM, Mori Y, et al. Dynamic changes in the expression of MicroRNA-31 during inflammatory bowel disease-associated neoplastic transformation. Inflamm Bowel Dis 2011;17:221-231. 
158. Rothwell PM, Fowkes FG, Belch JF, et al. Effect of daily aspirin on long-term risk of death due to cancer: analysis of individual patient data from randomised trials. Lancet 2011;377:31-41.

159. Aggarwal BB, Sung B. Pharmacological basis for the role of curcumin in chronic diseases: an age-old spice with modern targets. Trends Pharmacol Sci 2009;30:85-94.

160. Kanai M, Imaizumi A, Otsuka Y, et al. Dose-escalation and pharmacokinetic study of nanoparticle curcumin, a potential anticancer agent with improved bioavailability, in healthy human volunteers. Cancer Chemother Pharmacol 2012;69:65-70.

161. He ZY, Shi CB, Wen H, et al. Upregulation of p53 expression in patients with colorectal cancer by administration of curcumin. Cancer Invest 2011;29:208-213.

162. Delmas D, Lancon A, Colin D, et al. Resveratrol as a chemopreventive agent: a promising molecule for fighting cancer. Current Drug Targets 2006;7:423-442.

163. Tili E, Michaille JJ, Adair B, et al. Resveratrol decreases the levels of miR-155 by upregulating miR-663, a microRNA targeting JunB and JunD. Carcinogenesis 2010;31:1561-1566.

164. Aggarwal BB, Van Kuiken ME, Iyer LH, et al. Molecular targets of nutraceuticals derived from dietary spices: potential role in suppression of inflammation and tumorigenesis. Exp Biol Med 2009;234:825-849.

165. Fukase K, Kato M, Kikuchi S, et al. Effect of eradication of Helicobacter pylori on incidence of metachronous gastric carcinoma after endoscopic resection of early gastric cancer: an open-label, randomised controlled trial. Lancet 2008;372:392-397.

166. Ikeda K, Marusawa H, Osaki Y, et al. Antibody to hepatitis B core antigen and risk for hepatitis C-related hepatocellular carcinoma: a prospective study. Ann Int Med 2007;146:649-656.

167. Sato Y, Takahashi S, Kinouchi Y, et al. IL-10 deficiency leads to somatic mutations in a model of IBD. Carcinogenesis 2006;27:1068-1073.

168. Ando T, Yoshida T, Enomoto S, et al. DNA methylation of microRNA genes in gastric mucosae of gastric cancer patients: its possible involvement in the formation of epigenetic field defect. Int J Cancer 2009;124:2367-2374.

169. Nanjo S, Asada K, Yamashita S, et al. Identification of gastric cancer risk markers that are informative in individuals with past $\mathrm{H}$. pylori infection. Gastric Cancer 2012 (in press). 
170. Toyota M, Ahuja N, Ohe-Toyota M, et al. CpG island methylator phenotype in colorectal cancer. Proc Natl Acad Sci USA 1999;96:8681-8686. 
Table 1. Inflammation-associated cancers in digestive organs

Inflammation- Underling inflammation

associated cancer

Barrett's cancer

Reflux esophagitis

Gastric cancer

$H$. pylori-induced chronic gastritis

Colitic cancer

Inflammatory bowel disease

Celiac disease

HCC

HCV and HBV chronic hepatitis

Primary biliary cirrhosis

Cholangiocarcinoma

Primary sclerosing cholangitis

Pancreatic cancer

Chronic pancreatitis

Hereditary pancreatitis

Lymphoma

H. pylori-induced MALT lymphoma

$\mathrm{HCV}$-associated lymphoma

Celiac disease-associated lymphoma

HCC; hepatocellular carcinoma 


\section{Figure Legends}

Figure 1. Molecular link between inflammation, genetic and epigenetic alterations, and carcinogenesis. Inflammation contributes to ROS production and transcriptional upregulation of the DNA mutator enzyme, AID. These two factors were capable of inducing somatic mutations and chromosomal aberrations in tumor-related genes. On the other hand, inflammation results in mislocalization of DNMTs, inducing aberrant DNA methylation. The resulting genetic and epigenetic changes, including the activation of oncogenes, inactivation of tumor-suppressor genes, and dysregulation of DNA repair genes, could further enhance genetic instability, finally leading to carcinogenesis.

Figure 2. Mechanism of mutation induction by AID activity. AID deaminates cytosine (C), resulting in the generation of a uracil (U) and therefore can transform a DNA C:G pair into a $\mathrm{U}: \mathrm{G}$ mismatch. The AID-generated $\mathrm{U}: \mathrm{G}$ mismatch can be recognized by UNG or MSH2/MSH6 heterodimer and repaired correctly (a). If DNA replication starts before recognition by the repair system, a $\mathrm{U}: \mathrm{G}$ mismatch gives rise to $\mathrm{C} / \mathrm{G}$ to $\mathrm{T} / \mathrm{A}$ transition (b). Alternatively, generation of an abasic site by UNG (c) or recognition of the U:G mismatch by the MSH2/MSH6 heterodimer (d) induces any mutations in the AID-generated $\mathrm{U}: \mathrm{G}$ mismatch or at a nearby A:T site, respectively, in an error-prone manner (indicated as $\mathrm{M}$ ).

Figure 3. AID exerts both favorable and unfavorable effects. AID is a molecule that is indispensable for the diversification of immunoglobulin genes by inducing both somatic hypermutation and class-switch recombination in activated $\mathrm{B}$ lymphocytes. The genotoxic activity of AID, however, can be aimed to trigger the genetic alterations at both the nucleotide and chromosomal levels in not only B lymphocytes but also epithelial cells in the inflammatory conditions.

Figure 4. The degree of epigenetic field defects can be assessed using methylation levels of appropriate marker $\mathrm{CpG}$ islands, mostly passengers. Receiver-operating characteristic (ROC) curves were drawn to distinguish gastric mucosae of gastric cancer patients and those of healthy individuals with past infections by $H$. pylori. The ROC curves of newly isolated methylation risk markers, $\mathrm{CpG}$ islands \#3 and \#7, had a much larger area under the curve (AUC) values than those of two previously isolated markers, filamin $\mathrm{C} \gamma$ (FLNc) and thrombomodulin (THBD), reaching 0.78-0.84. Modified from 
Nanjo et $\mathrm{al}^{169}$.

Figure 5. Current model of aberrant DNA methylation induction by chronic inflammation. Cytokines, such as IL-1 $\beta$ and TNF- $\alpha$ from macrophages, and oxidative stress, such as NO, are likely to recruit EZH2 and DNMT1 to a promoter CpG island of a gene with a flag of H3K27 me3 and without protection by RNA polymerase II. Sparsely induced methylation leads to dense methylation with a low probability. 


\section{Inflammation}

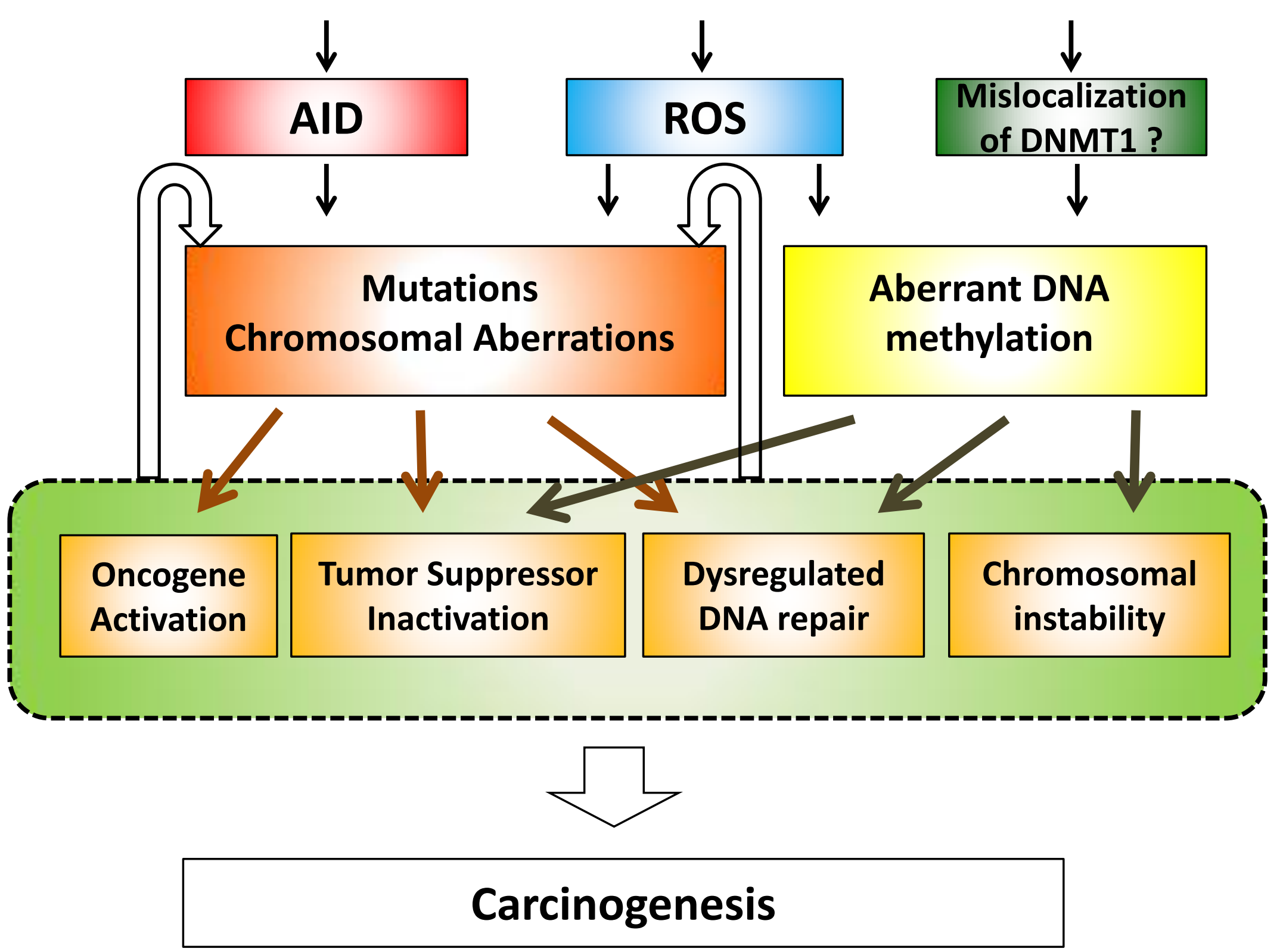




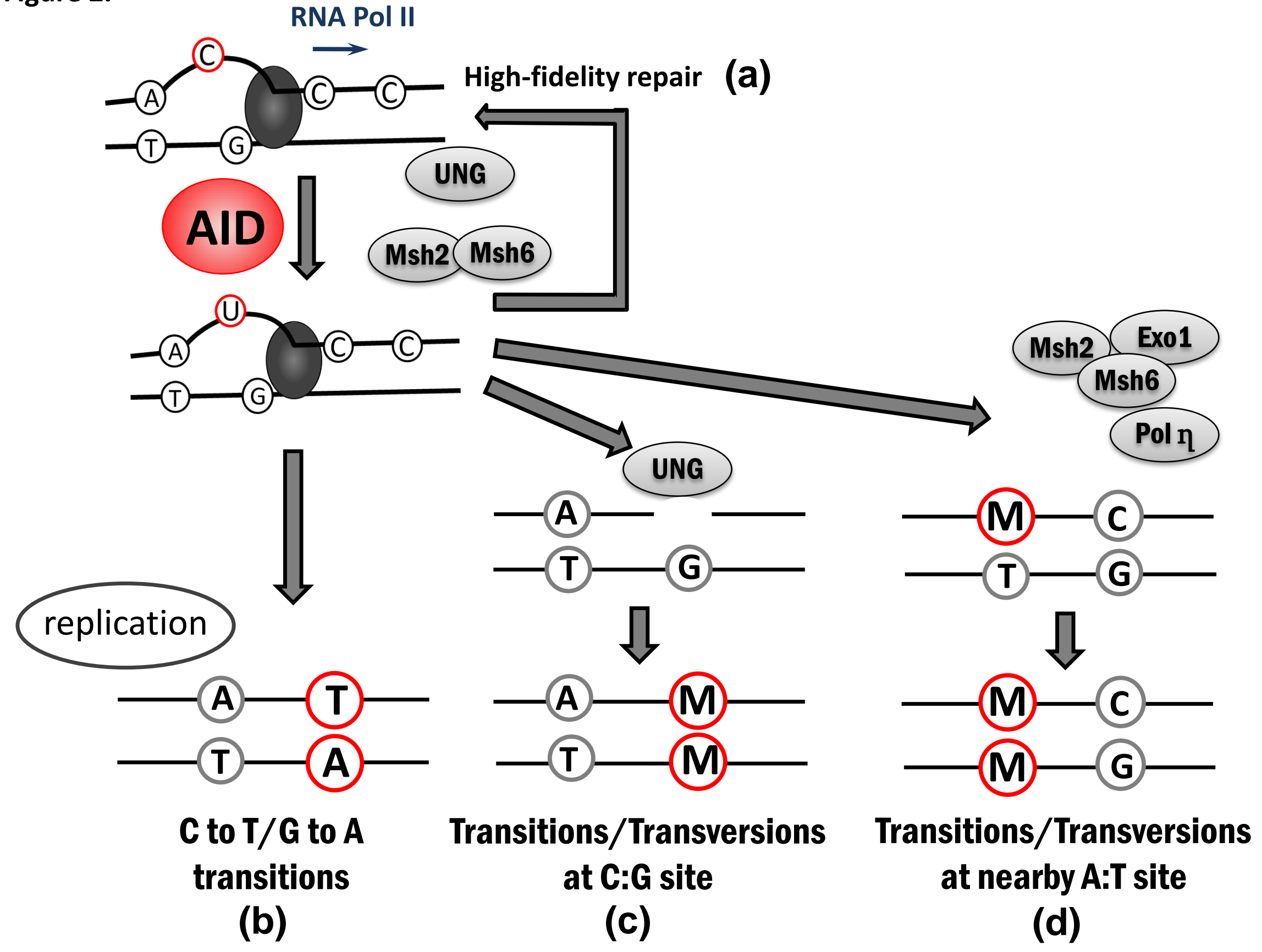




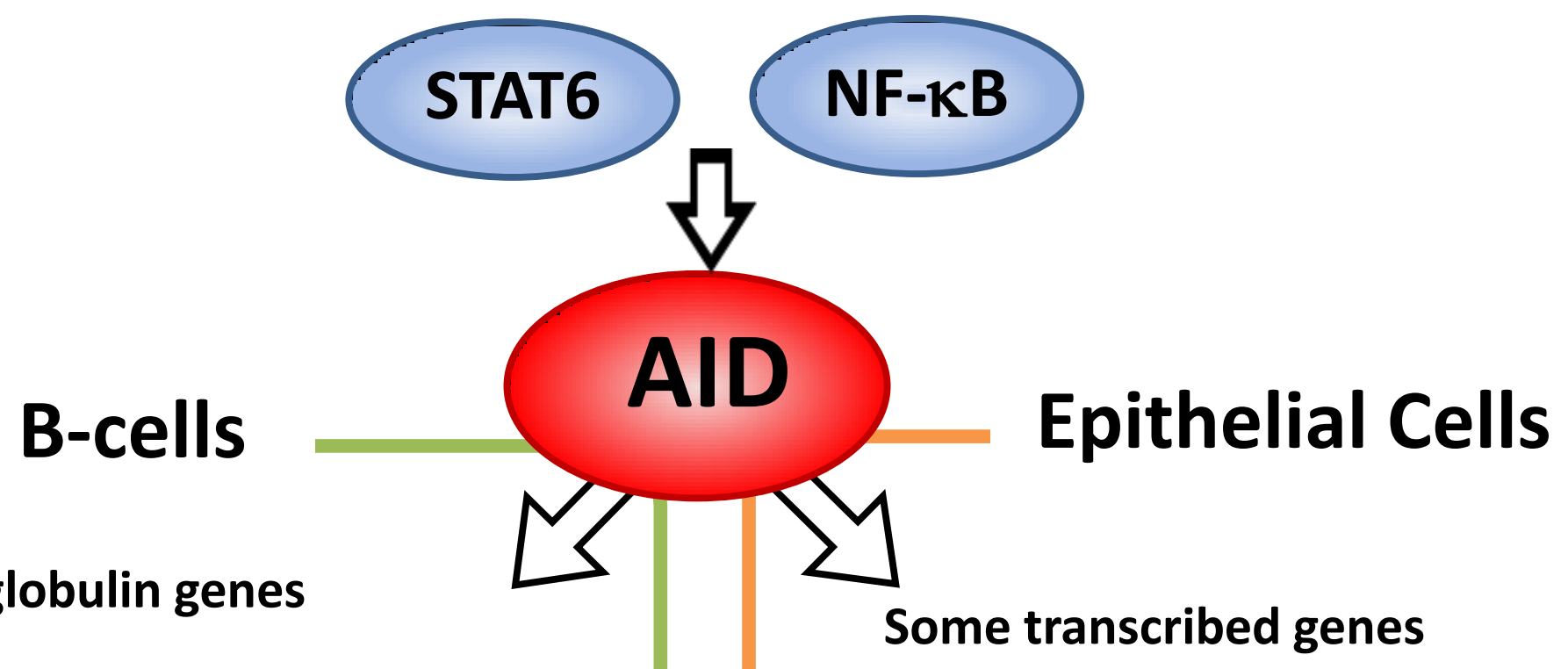

Somatic Hypermutations

Class-switch recombination

Some transcribed genes

Somatic Mutations MYC, PAX5, PIM1, miR142 etc Chromoromal Translocation MYC-IGH etc

Somatic Mutations TP53, MYC, CDKN2A etc Chromoromal Deletion

CDKN2A etc 


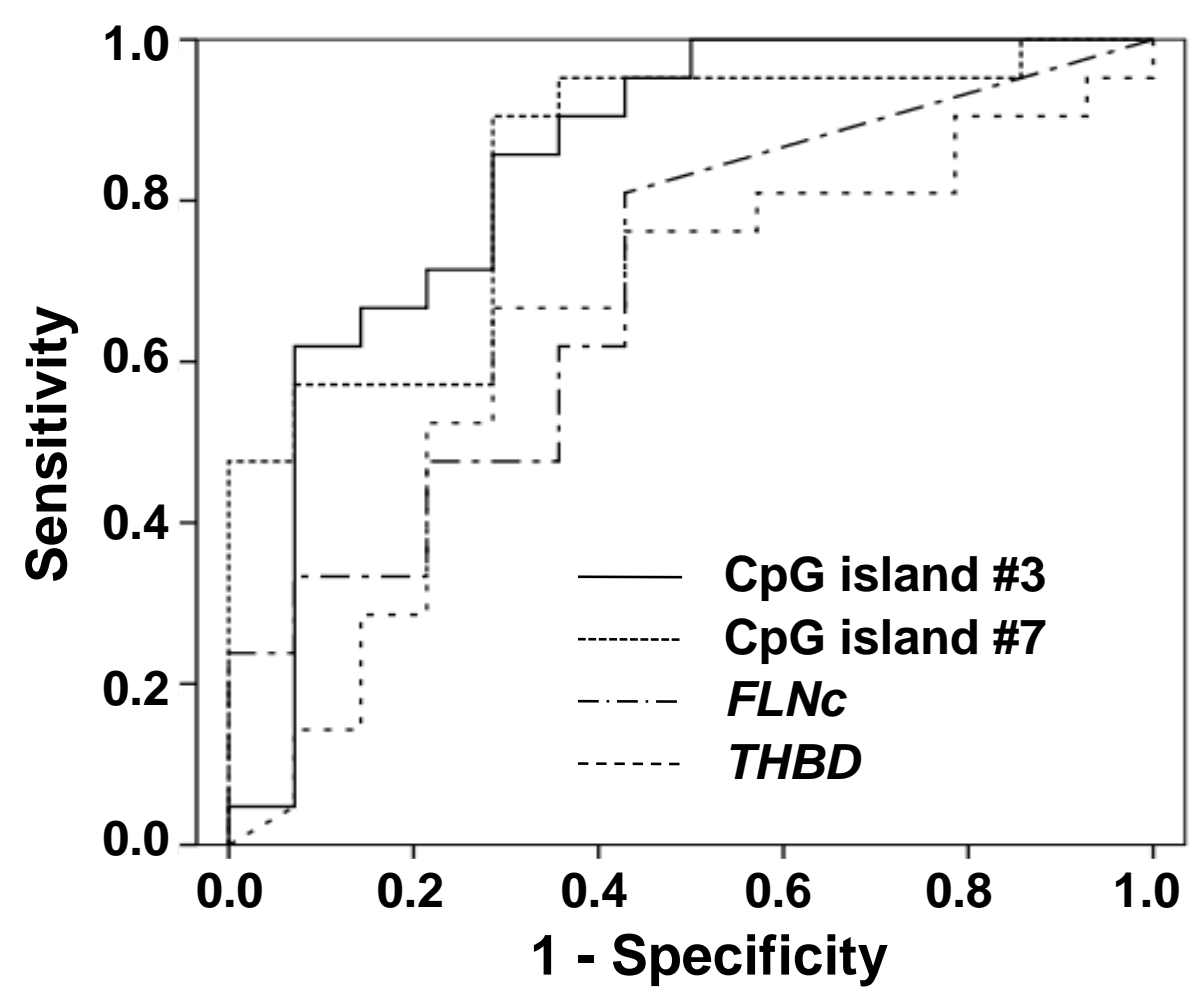


B
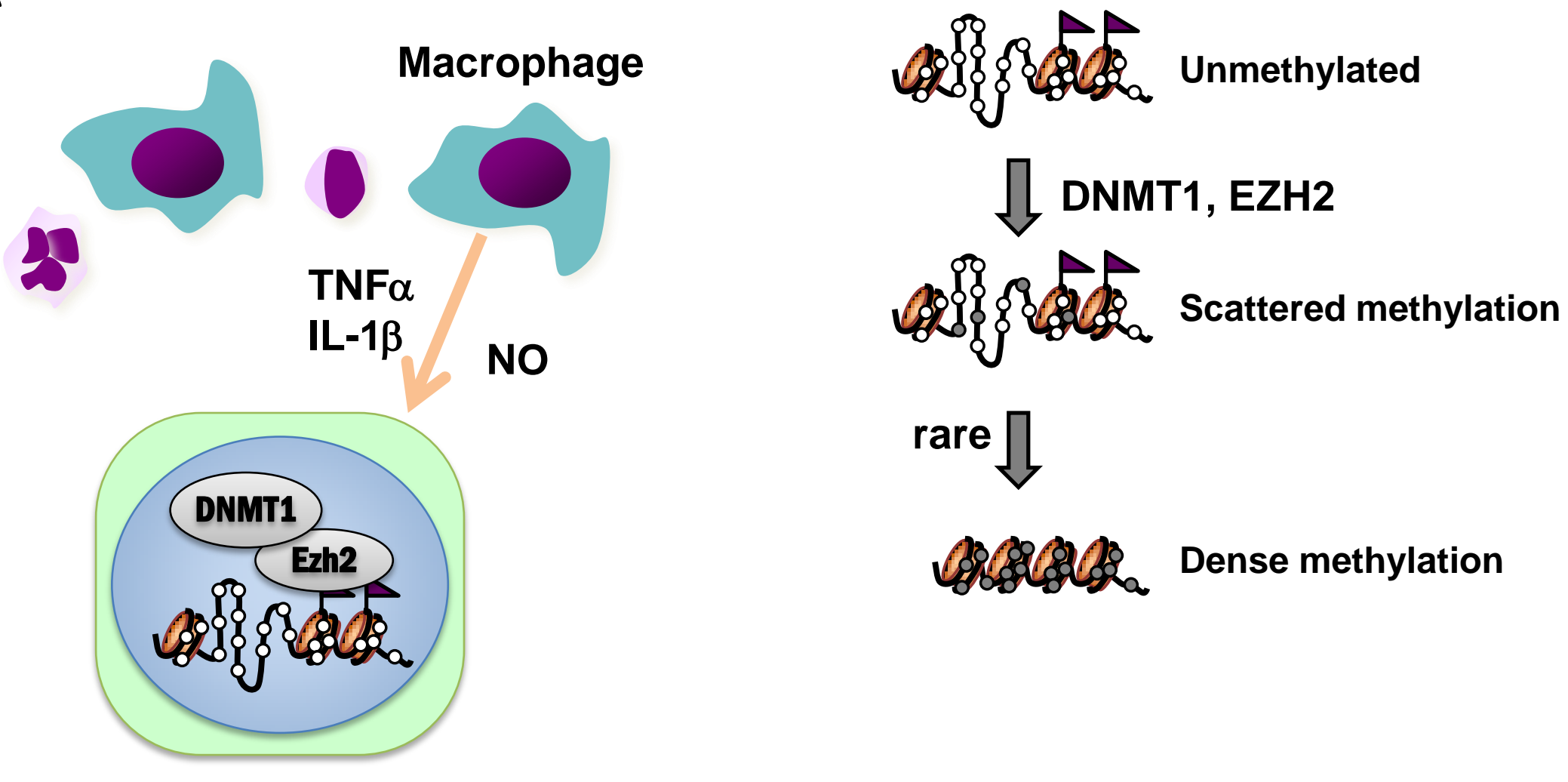

A H3K27me3

-o- Unmethylated CpG site

-o- Methylated CpG site

(b) Nucleosome 